\title{
HORTA ESCOLAR, EDUCAÇÃO AMBIENTAL E A INTERDISCIPLINARIDADE
}

\author{
Fabiane Rezende de Oliveira ${ }^{1}$ \\ Emmanuelle Rodrigues Pereira² \\ Antônio Pereira Júnior ${ }^{3}$
}

Resumo: O objetivo foi caracterizar a horta escolar como material didático para a transdisciplinaridade em ciências, matemática e português, no ensino fundamental maior ( $6^{\circ}$ e $7^{\circ}$ ano). Projeto de Assentamento Gleba Jacaré. Nova Ipixuna - PA. O método empregado foi 0 indutivo, com abordagem qualiquantitativa e de natureza aplicada. Os dados obtidos para a horta escolar indicaram que ela foi efetiva quanto a relação ensino-aprendizagem acerca das disciplinas envolvidas na pesquisa. Quanto aos dados para as atividades pedagógicas complementares (pesquisa de campo; elaboração de relatórios; discussões acerca da horta escolar e socialização do conhecimento; visitas técnicas a horta escolar), os dados indicaram que houve contribuição direta para a assimilação do conteúdo dessas disciplinas, bem como indicaram que há necessidade de mitigar a rejeição dos vegetais na merenda escolar $(63,2 \%$ fundamental menor; $38 \%$ - fundamental maior),

Palavras-chave: Alimentação Orgânica; Aprendizado Significativo; Ferramentas Educacionais. 


\section{Introdução}

\section{A horta ambiental}

Nas atividades escolares desenvolvidas, a horta escolar, utilizada como um recurso didático para o ensino das ciências (biologia, matemática e português) permite relacionar o teórico com o prático bem como a Educação Ambiental, ou seja, o conhecimento empírico com sistemático além do ambiental, e isso valoriza a apreensão das informações ofertadas, por essa prática ao educando, e esse conhecimento é adquirido no convívio familiar, além do convívio em sociedade.

A horta escolar permite relacionar a educação ambiental com educação alimentar e valores sociais, tornando possível a participação dos sujeitos envolvidos, desenvolvendo uma sociedade sustentável através de atividades voltadas para Educação Ambiental - EA. A EA deve ser tratada a partir de uma matriz que conceba a educação como elemento de transformação social apoiada no diálogo e no exercício da cidadania. Comportamentos ambientalmente "corretos" como, por exemplo, coleta seletiva, reutilização de garrafas de politeleftalato de etileno - PET, devem ser aprendidos na prática, no cotidiano da vida escolar, contribuindo para a formação de cidadãos responsáveis (CRIBB, 2010; RODRIGUES; FREIXO, 2009).

$\mathrm{Na}$ realidade, ela pode se tornar um instrumento facilitador do trabalho dos temas transversais, em especial dos seguintes: Meio Ambiente, Saúde, Trabalho e Consumo. Além disso, a horta pode também se tornar um ambiente integrador da comunidade escolar e instrumento para o ensino das diferentes disciplinas do ensino fundamental, propiciando atividades práticas e prazerosas a alunos, professores, funcionários e famílias (FROES et al., 2015).

Além disso, as aulas práticas despertam e mantém o interesse dos alunos; envolvem os estudantes em investigações científicas, no caso de ciências, como as raízes fixam os vegetais no solo; desenvolvem a capacidade de resolver problemas, pois, as hortas podem ter formas diversas como, por exemplo, retangular e, como isso, permitir o cálculo para a área da mesma, bem como compreender conceitos básicos na formação de parágrafos na composição de relatórios, aplicação verbal, identificação do sujeito, etc. (TAVARES et al., 2014).

Além disso, a horta escolar permite a relação entre educação alimentar, ambiental e valores sociais, possibilitando a interação dos sujeitos envolvidos, proporcionando uma sociedade sustentável através de atividades voltadas diretamente para a educação e suas diversas faces. A escola é, sem sombra de dúvidas, o melhor agente a promover uma instrução alimentar adequada, por ser na infância e adolescência que se formam esses hábitos (BATISTA et al., 2013).

Ademais, o uso dela, melhora o desempenho dos educandos tanto nas tarefas escolares não só na disciplina ciências, mas em todas as demais disciplinas curriculares normais, e eleva a visão acerca da sensibilidade 
ambiental, bem como haverá melhorias nos hábitos alimentares quando se aplica a construção de hortas escolares (FERREIRA et al., 2014).

Nesse contexto, 0 projeto horta escolar torna possível 0 desenvolvimento do processo de ensino-aprendizagem, por meio da prática, além de despertar valores sociais como participação, relação interpessoal, senso de responsabilidade e sensibilização quanto às questões relacionadas ao meio ambiente. Os alunos se tornaram capazes de analisar e discutir as melhores formas para manter um ambiente saudável, além de obterem um cuidado maior com a alimentação e a higiene (PEREIRA et al,, 2012).

Em face da sensibilização às questões ambientais, coube a escola o papel primordial de ser a facilitadora do acesso por parte dos educandos aos conhecimentos necessários para a sua construção enquanto sujeito atuante, construtor e modificador da realidade social, ou seja, de sua cidadania, então ao profissional da educação cabe um papel primordial nesse processo. Portanto, no caminho do efetivar a educação ambiental, ao professor incumbe a tarefa essencial de apontar o trajeto aos educandos, criar situações em que estes hajam de forma construtiva de modo a desenvolverem competências e habilidades, e possam refletir de forma crítica sobre a realidade de modo a adquirirem a consciência da necessidade da conservação ambiental (AGUIAR et al., 2017).

Quanto aos hábitos alimentares, uma de suas dimensões à incorporação do meio ambiente do ser humano por meio do ato de comer, de tal forma que o ambiente passa a compô-lo e este passa a compor o ambiente, o que resulta em um ser constituinte e constituído. Com isso, fica garantida a condição material de pertencimento humano que pode abrir caminho para o vislumbrar de outras dimensões. Logo, devido ao caráter multirreferencial do ser humano, as relações estabelecidas com o meio ambiente, entendido no sentido amplo da expressão, e condicionam a construção de seu bem-estar, de estar bem no mundo, de sua saúde e de sua felicidade (SILVA; FONSECA, 2011).

Consequentemente, a horta inserida no ambiente escolar torna-se um laboratório vivo de possibilidades no desenvolvimento de diversas atividades pedagógicas, unindo a teoria e a prática. É necessário que os educandos busquem relacionar os conhecimentos matemáticos com a realidade, dando sentindo ao aprendizado dos conceitos apresentados, como ferramenta importante para compreender a realidade em que vivem (TRENTIN; PEREIRA, 2014).

Outro fator, é que a horta escolar permite uma aula diferenciada de ciências com o intuito de possibilitar o aprendizado, somente ocorre em quatro condições básicas: a motivação, o interesse, a habilidade de compartilhar experiências e a habilidade de interagir com os diferentes contextos (SANTANA et al., 2014).

Consequentemente, sob o aspecto do aprendizado, são as aulas práticas acerca as definições de solo e a importância de um manejo ecológico, focando na importância de componentes como a matéria Revbea, São Paulo, V. 13, № 2: 10-31, 2018. 
orgânica, microrganismos, água, ar, estruturas físicas bem estruturadas e nutrientes para um solo fértil e biologicamente ativo, que melhoram a assimilação dos conteúdos de ciências (CORBARI et al., 2014).

Em relação ao procedimento de sensibilização da escola, ele pode causar iniciativas que excedam seu ambiente, expandir-se pela comunidade escolar e circunvizinhança, para levar informações e atividades correlacionadas à educação alimentar e ambiental desenvolvida na escola (BATISTA et al., 2013), pois, a utilização do alimento orgânico como um dos elementos do projeto pedagógico pode abrir possibilidades de novas abordagens educativas para estudantes, professores e dirigentes (CUNHA; SOUZA; MACHADO, 2010).

\section{A Educação Ambiental}

Entende-se por Educação ambiental - EA, o conjunto de ações de caráter que potencializam de maneira significativa a sensibilidade ambiental dos educandos. Ela pode ser formal ou informal. No caso do processo formal, pode ser ministrada em diferentes disciplinas (Ex.: ciências, matemática e português), respeitando as especificidades de cada uma delas (SBAZÓ JÚNIOR, 2010).

A EA, de acordo com a Lei n. $9795: 99$, art. $4^{\circ}$, é o processo por meio do qual o indivíduos e a coletividade constroem valores sociais, conhecimentos (ex.: a reutilização de resíduos sólidos), habilidades como a construção e manutenção de hortas; atitudes, como a sensibilidade em relação a conservação ambiental, e competências voltadas para a conservação do meio ambiente, bem de uso comum do povo, essencial à sadia qualidade de vida e sua sustentabilidade (PNEA, 1999).

Grande parte das atividades de Educação Ambiental na escola é desenvolvida dentro de uma modalidade formal. Os temas, em geral, são poluição (solo, água, ar), reciclagem do lixo, conservação da natureza, entre outros. $O$ fato é que, no Ensino Fundamental, a EA, tem que ser voltada à sensibilização dos alunos em relação aos problemas ambientais, além de trabalhar a percepção do ambiente e gerar um pensamento crítico (SIQUEIRA et al.,2016).

\section{A interdisciplinaridade}

O termo interdisciplinaridade, como muitos veiculam, foi criado no século XX, mas sua função é a de executar ideias muito antigas, como as de Platão e Aristóteles, que acreditavam na unicidade do conhecimento, na totalidade. Porém, a interdisciplinaridade propõe duas perspectivas de estudo. Ela é de ordem epistemológica e outra de ordem curricular, ou seja, a primeira delas, produziu avanços ao explorar aquele conceito como um diálogo integrativo entre diferentes disciplinas (CONRADO; SILVA, 2017).

revista brasileira educação ambiental 
Como o início de uma horta na escola exige outros conhecimentos, além da Educação Ambiental, sua implantação e implementação se torna interessante para trabalhar com os conteúdos curriculares das áreas de ensino que compõem a base de ensino das escolas de Ensino Fundamental (COIMBRA, 2010).

A título de exemplo, podemos destacar: nas Ciências, ciclo de cultivo, ecossistema, fotossíntese; na geografia, características do solo, irrigação do solo; na matemática, cálculo de área, distribuição e disposição dos canteiros; na história, relações de produção, relações do homem com a natureza, transformações ao longo da história dos hábitos alimentares; na língua portuguesa, pesquisa de textos sobre a importância de uma alimentação saudável, produção de material de divulgação na comunidade das ações desenvolvidas pelos alunos na implementação da horta escolar, etc. (MALACARNE; ENISWELER, 2014).

Com base nesses argumentos, o presente trabalho se reveste de grande importância para a comunidade escolar de ensino fundamental, seja I ou II, porque mostra que a horta escolar utilizada como material didático pedagógico no ensino das ciências (biologia, matemática e português) para educandos do sexto e sétimo ano do ensino fundamental II no município de Nova Ipixuna, Sul do estado do Pará, e como melhora e desempenho deles, nessas, e em outras disciplinas.

\section{Material e métodos}

\section{Fisiografia do município}

O município de Nova Ipixuna (Figura 1, próxima página), localiza-se a $525 \mathrm{~km}$ da capital, Belém. Possui uma área de 1.564, $184 \mathrm{Km}^{2}$, as coordenadas geográficas de localização do município são as seguintes: 045' $16^{\prime \prime}$ de latitude sul e 4904'37'" de longitude Oeste.

A população do município é de 15. 632 habitantes (IBGE, 2014), o relevo é originário de rochas pré-cambrianas já bastante erodidas, resultando, atualmente, em áreas planas e grandes elevações, clima tropical úmido, com inverno seco, na transição dos tipos Aw/Am (classificação de Koppen). A temperatura média anual oscila entre $26^{\circ} \mathrm{C}$ a $27^{\circ} \mathrm{C}$, com máxima de $31^{\circ} \mathrm{C}$ a $32^{\circ} \mathrm{C}$, e a mínima de $22^{\circ} \mathrm{C}$ a $23^{\circ} \mathrm{C}$. A precipitação pluviométrica anual fica entre $2.000 \mathrm{~mm}$ e $2.250 \mathrm{~mm}$. O período mais chuvoso estende-se de novembro a abril. Com 125 a 150 dias de chuva. A vegetação original predominante é a floreta tropical, onde são encontradas espécies, como: ipê (Tabebuia spp), castanheira (Bertholletia excelsa Ducke), e outras espécies arbóreas (PMNI, 2006). 


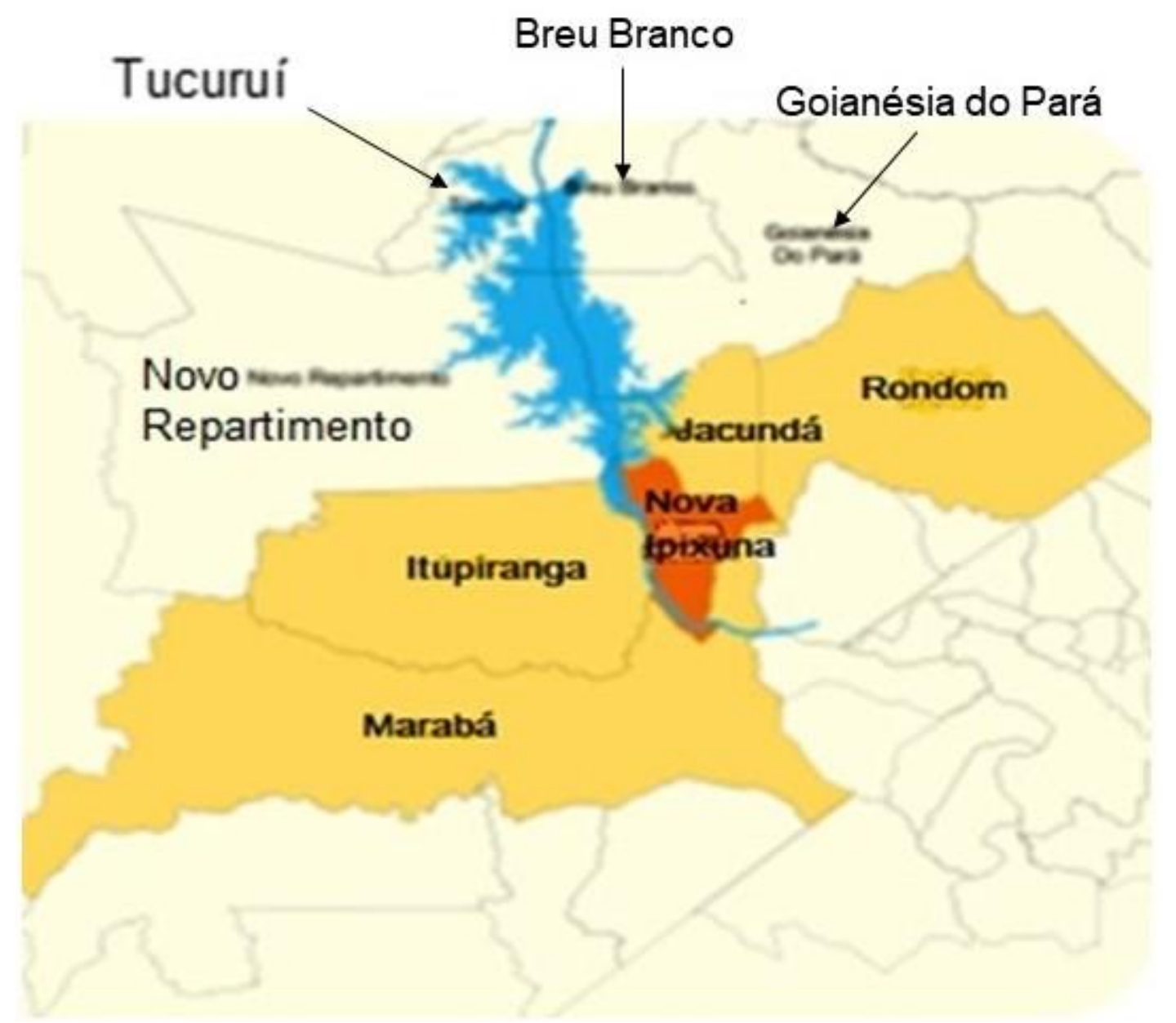

Figura 1: Município de Nova Ipixuna e os municípios limítrofes.

Fonte: Adaptado a partir do original da Prefeitura Municipal de Nova Ipixuma - PMNI (2006).

Ainda de acordo com essa fonte, os principais rios que cortam o município são Jacundá e o Tocantins. O Projeto de Assentamento Gleba Jacaré dista vinte e oito $\mathrm{km}$ de Nova Ipixuna, possui atualmente cinquenta e nove famílias assentadas, com produtividade econômica de pecuária leiteira, agrícola (em desenvolvimento).

\section{Materiais e olerícolas}

Para a revitalização da horta escolar, utilizou-se resíduos reaproveitáveis, e olerícolas (Tabela 1), doadas pelas responsáveis pelos educandos. 
Tabela 1: Materiais e olerícolas utilizadas na Horta Escolar. E.M.E.F.

Santo Antônio do Praialta - Nova Ipixuna - PA.

\begin{tabular}{llll}
\hline \multicolumn{2}{c}{ Materiais } & & Olerícolas \\
\hline Materiais & Qtde. & Nome vulgar & Nome científico \\
\hline Enxada (1) & 03 & Abobora & Cucurbita moschata \\
Rastelo (1) & 03 & Alface crespa & Lactuta sativa v. crispa \\
Carro-de-mão (1) & 01 & Cebolinha & Allium fistulosum \\
Garrafa PET ${ }^{*}(2)$ & 360 & Coentro & Coriandrum sativum \\
Terra Preta (2) & 120 & Couve-crespa & Brassica oleracea \\
Exterco de gado (2) & & Melancia & Citrullus lanatus var.lanatus \\
& & Pimenta de cheiro & Capsicum chinense \\
& & Tomate & Solanum lycorpesicum \\
\hline
\end{tabular}

Legendas: Qtde: quantidades (1) - unidades; (2) quilograma; * poli tereftalato de etileno Fonte: autores (2017).

É necessário que se esclareça que olerícola é uma palavra derivada do Latim, onde: olus, significa hortaliças, e colere, significa cultivar. Para hortaliças, a Comissão Nacional de Normas e Padrões para Alimentos CNNPA, Decreto-Lei n. 986:1969 (ANVISA, 1978), elaborou a seguinte definição: é uma planta herbácea da qual uma ou mais partes são utilizadas como alimento na forma natural. A verdura, nesse Decreto-lei, foi definida como as partes verdes (couve, alface, cebolinha, coentro) das hortaliças que irão servir de alimentos. Os legumes são assim denominados quando as sementes ou frutos (tomate, melancia e pimenta de cheiro) das hortaliças servirem se alimentos (especialmente as leguminosas), e as raízes (macaxeira), tubérculos (batatas) e rizomas (bananeiras)

\section{Métodos}

Para a presente pesquisa, o método aplicado foi o indutivo que, de acordo com Gil (2008), onde o conhecimento é fundamentado em experiências. Nesta pesquisa, partiu-se do conhecimento dos educandos sobre educação ambiental e como a horta escolar pode contribuir para a melhor relação homem - natureza, associada aos estudos de ciências, matemática e português.

Em relação a abordagem, a pesquisa é qualiquantitativa. De acordo com Silveira e Córdoba (2009), uma pesquisa qualitativa busca o porquê das coisas e exprime-se o que convém ser feito, por isso, se buscou saber qual a experiência que os educandos possuem acerca da associação entre EA e a relação homem-natureza.

A pesquisa também é classificada como quantitativa porque essas autoras afirmam que os resultados da pesquisa qualitativa podem ser quantificados, em função disso, expressaram-se os dados qualitativos com base no universo de educandos e docentes participantes dessa pesquisa, bem como o uso dos recursos matemáticos com o uso da estatística descritiva sobre o grau de conhecimento sobre EA, horta escolar e a relação homemnatureza. 
Finalmente, quanto a natureza, a pesquisa foi caracterizada como aplicada porque deve gerar conhecimentos que permitam a solução do problema, ou seja, se os educandos e docentes revelaram baixa compreensão na relação homem - natureza, esta pesquisa deverá apresentar a(s) possível (eis) solução (ões) que elevem o nível dessa compreensão. Para melhor aplicabilidade desse método, ele foi dividido em seis etapas (Figura 2).

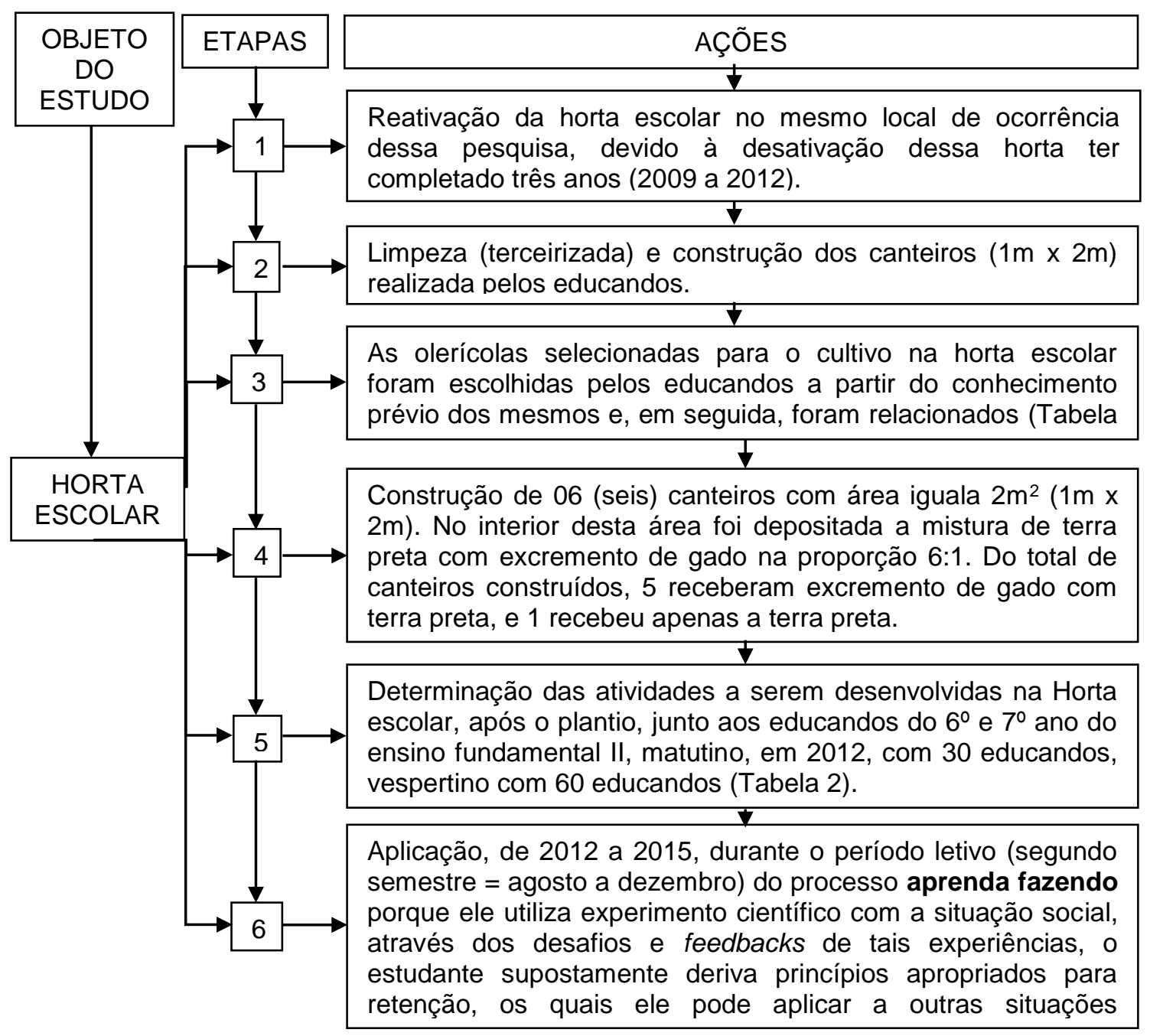

Figura 2: Fluxograma metodológico do estudo

Fonte: autores (2017).

Vale ressaltar que a revitalização da horta escolar, implantada por outro docente em 2009, e ficou desativa por três anos, ou seja, até 2012, conforme descrito na etapa 1. Como a pesquisadora necessitava melhorar o interesse e a compreensão dos educandos, quanto ao conteúdo de botânica e, resolveu revitalizar a horta e utilizá-la como ferramenta pedagógica, para complementar, a pesquisadora expôs a ideia aos docentes de português e matemática, e os mesmos abarcaram a proposta apresentada. Dessa forma, a horta foi revitalizada para que promovesse a interdisciplinaridade. 


\section{Local da pesquisa}

A pesquisa foi realizada na Escola Municipal de Ensino Fundamental Santo Antônio do Praialta- Projeto de Assentamento Jacaré (Figura 3).

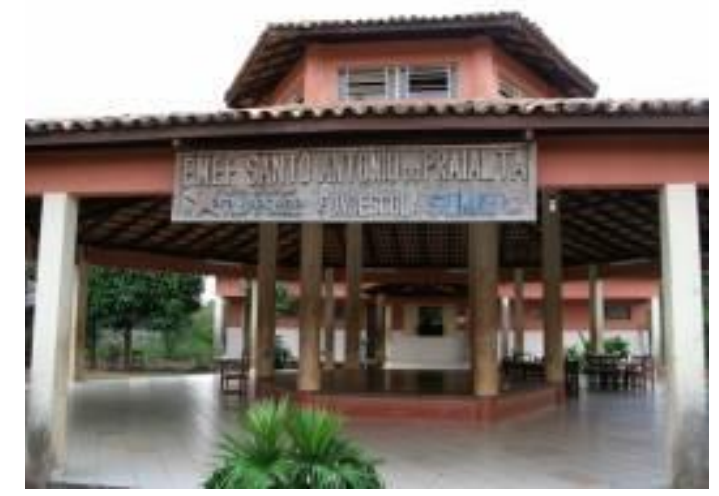

Figura 3: Vista frontal da E. M. E. F. Santo Antônio do Praialta, onde foi desenvolvida a pesquisa - Nova Ipixuna - PA. Fonte: autores (2017).

A E. M. E. F. Santo Antônio do Praialta, localiza-se no município de Nova Ipixuna, no Sudeste do Pará, e atende aos educandos do sexto e sétimo ano do ensino fundamental II. Essa escola funciona em três turnos (matutino, vespertino e noturno), porém, a pesquisa foi efetuada apenas nos turnos matutino e vespertino porque a pesquisadora atua em ambos. Nesses dois turnos, há dez turmas (cinco matutinas e cinco vespertinas) com um total de duzentas e trinta e oito educandos frequentes. Possui um corpo administrativo formado por um diretor (atualmente), uma coordenadora pedagógica, e uma secretária. O corpo docente é formado por dez professores, e um corpo auxiliar (merendeira, vigia, servente) constituído por sete colaboradores. Justifica-se a escolha dessa Unidade Educacional, devido a relação empregatícia entre a pesquisadora e essa Unidade.

\section{Atividades desenvolvidas pelos educandos}

As atividades desenvolvidas na horta escolar, após o plantio das olerícolas nas turmas de sexto e sétimo ano (fundamental II), nas disciplinas de ciências, português e matemática (Tabela 2). 
Tabela 2: Atividades desenvolvidas pelos educandos. E. M. E. F. Santo Antônio do Praialta. Nova Ipixuna - PA.

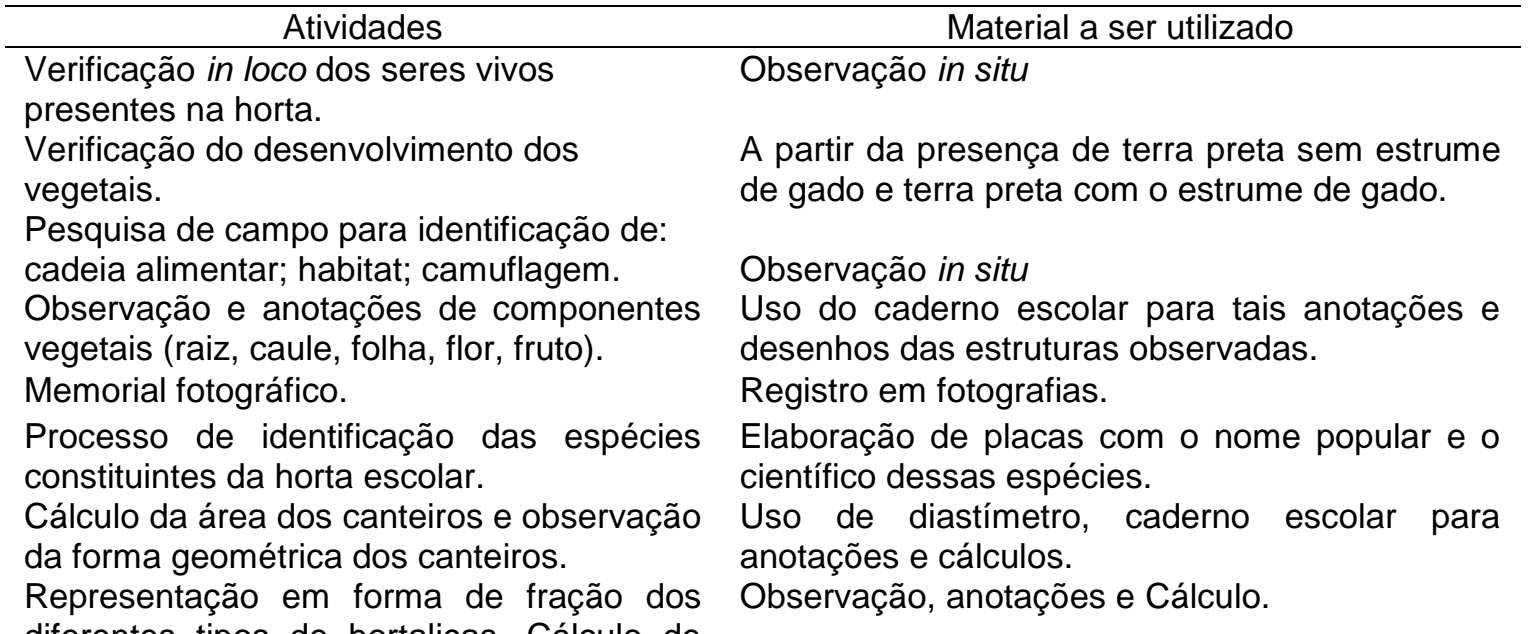
diferentes tipos de hortaliças. Cálculo de adição, subtração, multiplicação e divisão.

Relatório sobre a construção da horta e Caderno e caneta/lápis escolar. exposição do que foi feito na horta escolar.

Fonte: autores (2017).

\section{Resultados e discussão}

\section{Revitalização da horta escolar: Limpeza do local para revitalização da horta e construção dos canteiros}

Em agosto de 2012, a horta foi revitalizada em duas etapas: (1) limpeza do lugar efetuada por terceiros e (2) construção de canteiros ( $1 \mathrm{~m} \times 2 \mathrm{~m})$, com a participação direta de 16 educandos da turma do sétimo ano A os mesmos foram construídos com garrafas Tereftalato de Polietileno - PET (Figura 4, próxima página). Tais ações ocorreram para que fosse aplicada a Educação Ambiental (PNEA, 1999), e o conjunto de medidas adotadas a partir da Conferência da Terra que foi realizada no Rio de Janeiro em 1992, associado a política dos 5 R's: reduzir, repensar, reaproveitar, reciclar e recusar ${ }^{4}$.

Estudos efetuados por Braz et al. (2008) e Silva et al. (2014), concluíram que o envolvimento dos educandos nos cálculos das áreas e perímetros onde a horta escolar irá ser alocada, número de covas a ser aberto, bem como o de sementes a serem utilizadas e a quantidade de plantas por canteiros, é uma das formas de participação efetiva dos educandos na construção/revitalização de hortas com essa finalidade. Em Nova Ipixuna, ocorreu o envolvimento dos educandos, e os mesmos se mostraram bastante participativos.

${ }^{4}$ http://www.mma.gov.br/informma/item/9410-a-pol\%C3\%ADtica-dos-5-r-s 


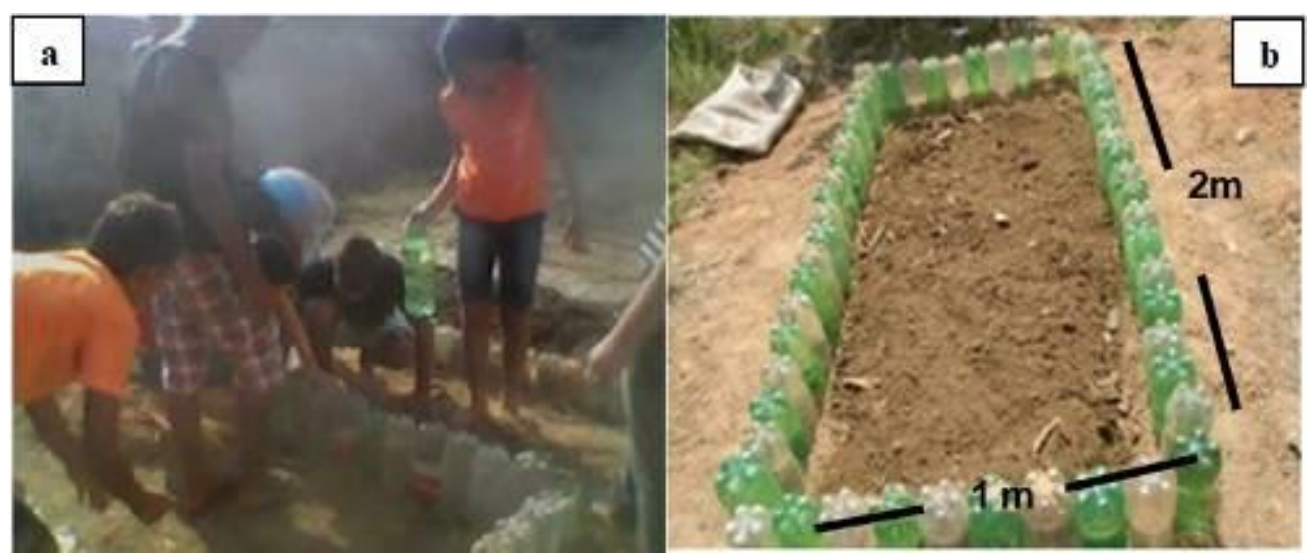

Figura 4: a) Educandos delimitando os canteiros da horta escolar com o uso de garrafas PET; b) Canteiro totalmente delimitado por garrafas do mesmo material ( $1 \mathrm{~m} \times 2 \mathrm{~m})$ - E. M. E. F. Santo Antônio do Praialta. Nova Ipixuna - PA. Fonte: autores (2017).

Essa afirmativa é baseada nos dados obtidos e analisados, pois estes indicaram que, durante esse período, todos os educandos do sétimo ano A, participaram na busca de garrafas Tereftalato de Polietileno - PET, que são descartadas nas proximidades dos rios e ruas da vila Assentamento jacaré. Como consequência, a limpeza desses lugares que são sujos com o descarte em lugares inadequado dessas garrafas. Ação desse tipo contribui para que os educandos venham a ser cidadãos ambientalmente alfabetizados.

No estudo efetuado em Piracicaba - SP, por Tavares e Rogado (2008), os autores concluíram que, em três instituições de ensino fundamental, a quantidade de educandos componentes da quinta série (sexto ano), variou entre onze e doze que participaram da construção de uma horta escolar, onde receberam a missão de resgatar garrafas PET, copo descartável de extrato de tomate para servirem de suporte para desenvolvimento das sementes obtidas e isso contribuiu para mitigar a geração de resíduos sólidos no meio ambiente.

\section{Quanto ao desenvolvimento das plantas} etapas.

Para observação do desenvolvimento das plantas foram efetuadas duas

Etapa 1: coleta de sementes e mudas: elas foram obtidas nas próprias residências dos educandos, além de mudas e sementes de hortaliças: cebolinha, couve, alface e coentro. Nesse momento foi perceptível a participação dos responsáveis que acreditaram nesse método educacional. 0 adubo usado na plantação dos vegetais foi excremento dos bovinos colhidos nas fazendas próximas à escola.

Etapa 2: semeadura e fixação das plântulas: A partir dessa ação, ou 
dados obtidos e analisados indicaram que ocorreu o desenvolvimento de cinco espécies plantadas (62,5\%). A análise desses dados também indicou que apenas 3 olerícolas (abóbora, melancia e tomate $=37,5 \%$ ) não desenvolveram (Tabela 3).

Tabela 3: Tipos e Desenvolvimento das olerícolas na Horta Escolar em 2012 - E.M.E.F. Santo Antônio do Praialta - Nova Ipixuna - PA.

\begin{tabular}{llc}
\hline Nome vulgar & Espécie & $\mathrm{D}(\%)$ \\
\hline Abóbora & Cucurbita spp & $\mathrm{ND}$ \\
Alface crespa & Lactuta sativa v. crispa L. & 100 \\
Cebolinha verde & Allium fistulosum L. & 75 \\
Coentro & Coriandrum sativum L. & 100 \\
Couve crespa & Brassica oleracea L. & 100 \\
Melancia & Citrullus lanatus (Thumb) Matsum \& Nakai var. lanatus & ND \\
Pimenta de cheiro & Capsicum chinense Jacq. & 78 \\
Tomate & Solanum lycorpesicum L. & ND \\
\hline \multicolumn{2}{l}{ Legendas: D - Desenvolvimento; ND - Não desenvolvido. Fonte: autores (2017). }
\end{tabular}

A análise dos dados obtidos, indicou que a prática quanto a mensuração da quantidade de sementes utilizadas e aquelas que realmente brotaram, permitiu a elaboração de tabelas para as anotações desses dados, e isso contribuiu para um melhor entendimento do uso da matemática, com relação a medidas e unidades métricas no cotidiano dos educandos, pois, a maioria deles, são filhos de agricultores locais e podem mostrar aos pais, a necessidade de um plantio racional com o uso de cálculos matemáticos.

Em relação a Ciências - Botânica, a professora responsável pela pesquisa, utilizou os dados sobre o desenvolvimento das plantas, para explicação sobre epicarpo, mesocarpo e endocarpo. Desse modo, os educandos obtiveram mais facilidade na assimilação da disciplina quanto a germinação de cultivos. A docente explanou também sobre a etapa de formação do fruto e porque três deles: abóbora (Figura 5a), tomate cereja (Figura 5b) e melancia (Figura 5c), não tiveram desenvolvimento total do mesocarpo, com desenvolvimento primário apenas no endocarpo e o epicarpo.

Quanto a Língua portuguesa, os educandos tiveram a oportunidade de aprender a relacionar objetos em ordem alfabética, sob a forma de lista/rol, onde inserem conhecimentos sobre a estética da escrita. Na pesquisa realizada em Iporá - GO, por Batista et al. (2013), foi indicado que, além de ciências e matemática, o português tem a característica de gerar e permitir a exploração de ideias acerca da pesquisa com a construção de relatos sobre o que foi efetivado na horta escolar.

Nesse contexto, é importante ressaltar que as espécies: abóbora ( $C$. $s p p)$, tomate cereja ( $S$. lycorpesicum), e melancia (C. lanatus var. lanatus), não desenvolveram por não ter no solo os nutrientes necessários. Outras espécies como: alface crespa ( $L$. sativa $v$. crispa), cebolinha verde ( $A$. fistulosum), coentro ( $C$. sativum), e pimenta de cheiro ( $C$. chinense). Apesar de serem plantadas em uma mesma área, desenvolveram, já que o local onde foram plantadas houve a reposição de adubo (excremento de gado). 


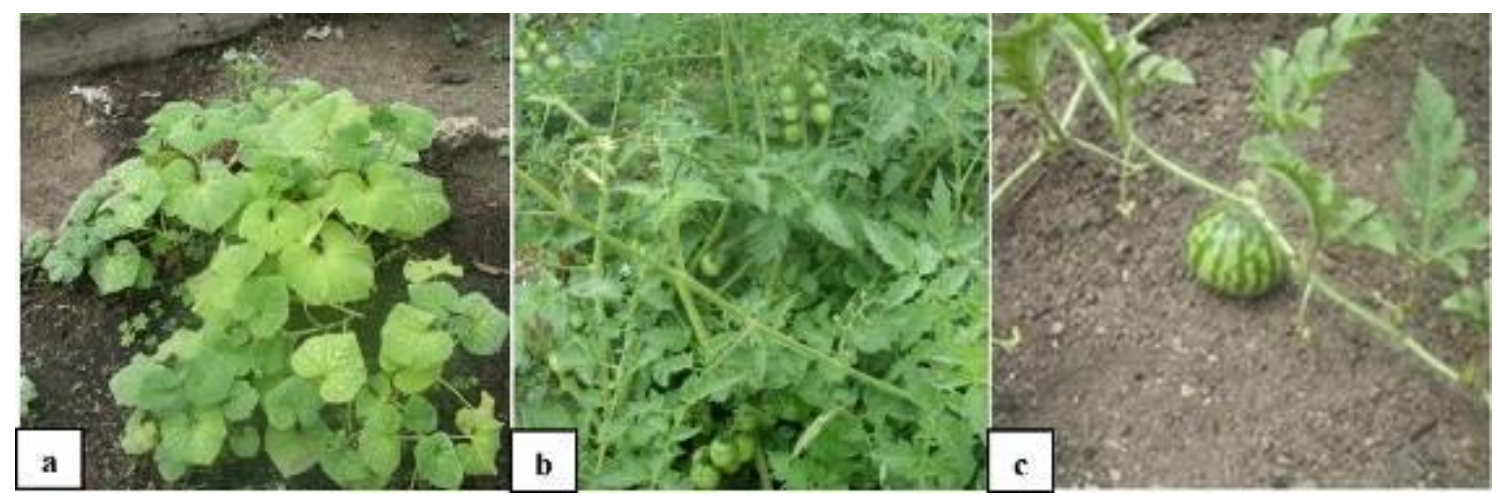

Figura 5: a) O desenvolvimento da abóbora (Cucurbita spp) na germinação e com um crescimento reduzido, não chegou ao desenvolvimento do fruto (pericarpo); b)

Desenvolvimento do tomate cereja (Solanun lycorpesicum L.), o fruto não desenvolveu ao ponto de ser consumida (mesocarpo); c) Melancia (Citrullus lanatus (Thunb.) Matsum. \& Nakai var. lanatus) com o desenvolvimento do endocarpo, no entanto o mesocarpo não desenvolveu, o fruto ficou com tamanho máximo de $5 \mathrm{~cm}$ de altura. E. M. E. F. Santo Antônio do Praialta Nova Ipixuna - PA. Fonte: autores (2017).

A partir desses dados analisados, a docente inferiu questões sobre as quantificações de substâncias para melhorar a riqueza nutricional do solo. Nesse caso, houve associação com o docente de matemática que contribuiu com a explicação sobre as proporções efetuadas nas misturas da terra preta com o Exterco de gado.

A docente em Ciências, a partir do crescimento dos vegetais, mostrou que apesar das semeaduras da couve crespas (B. oleracea) terem ocorrido ao mesmo tempo, e em uma mesma área, e distribuídas entre três canteiros (dois com terra preta + excremento de boi; um com terra preta), analisou o tamanho crescimento foliar e caulinar desse vegetal, e explanou que a área cujo substrato era apenas a terra preta (Figura 6a) o, foi menor, quando comparado com o substrato associado (Figura 6b), ou seja, terra preta e excremento de boi.

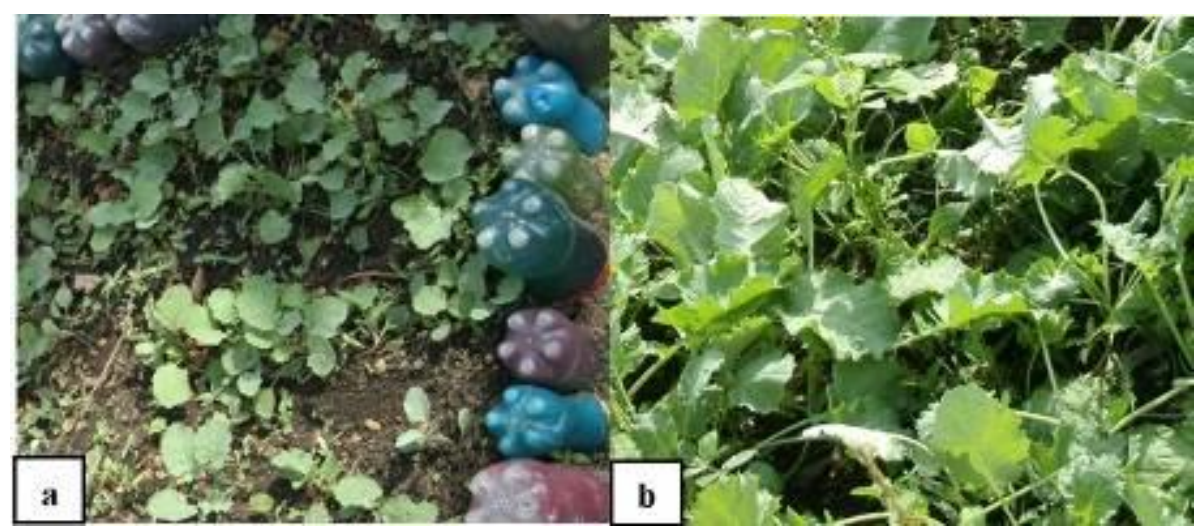

Figura 6: a) Couve crespa (B. oleracea) plantada, no canteiro sem a presença do excremento de gado, e b) com a presença do excremento de gado. E. M. E. F. Santo Antônio do Praialta Nova Ipixuna - PA. Fonte: autores (2017). 
No estudo efetuado em Brasília - DF, por Galvão, Salcedo e Oliveira (2008), os autores concluíram que a comparação de solos que receberam o excremento de gado e solos que não receberam, foram utilizados para a agricultura. Esse estudo ainda retrata a importância econômica do excremento de gado como fonte de renda para o agricultor, no caso de venda do produto, e como um meio de repor ao solo os nutrientes retirados pelas culturas. Nesse contexto, os resultados obtidos no presente estudo corroboram com a pesquisa elaborada em Brasília.

\section{Construção de conceitos e ações participativas, coletivas, vinculadas à educação ambiental, sustentabilidade alimentar e à cidadania}

Os dados obtidos e analisados para esse tema, indicaram que as ações praticadas pelos educandos de sexto e sétimo ano contribuem na construção de cidadãos sensíveis quanto ao cuidado com o ambiente, além de se tornar autônomos na transformação do ambiente de forma positiva na relação entre Educação Ambiental, fertilidade do solo, cobertura vegetal. Isso mostrou aos educandos a necessidade de conservar o solo para a produção de alimentos e que o uso correto do mesmo, incrementa uma melhor qualidade de vida.

No estudo efetuado em Pinhais - PR, por Corbari (2014), concluiu que os experimentos foram realizados abordando a ação da cobertura no solo, porosidade, crescimento radicular, problemas de erosão, diferentes texturas do solo, adubação orgânica, sistemas sustentáveis, indicadores de fertilidade do solo, diferença entre solos, intemperização, gênese do solo e qualidade ambiental. Em Santo Antonio do Praialta, foi verificado que as ações para implantação da horta escolar, o uso de excremento de gado, terra preta, recobertura do solo com cultivos nutricionais para associação na merenda escolar, obteve resultados similares àqueles obtidos em Pinhais.

Os dados obtidos e analisados para a manutenção da horta escolar, indicou que manutenção da horta escolar (sob a responsabilidade dos educandos da turma do sétimo ano $\mathrm{A}$, com quinze educandos, os educandos trabalharam com escala de revezamento para promover a limpeza (Figura 7a) e irrigação dos canteiros (Figura 7b).

Quanto a Língua portuguesa, os educandos tiveram a oportunidade de aprender a relacionar objetos em ordem alfabética, sob a forma de lista/rol, onde inserem conhecimentos sobre a estética da escrita. $\mathrm{Na}$ pesquisa realizada em Iporá - GO, por Batista et al. (2013), foi indicado que, além de ciências e matemática, o português tem a característica de gerar e permitir a exploração de ideias acerca da pesquisa com a construção de relatos sobre o que foi efetivado na horta escolar.

Nesse contexto, é importante ressaltar que as espécies: abóbora $(C$. $s p p)$, tomate cereja (S. lycorpesicum), e melancia (C. lanatus var. lanatus), não desenvolveram por não ter no solo os nutrientes necessários. Outras espécies como: alface crespa ( $L$. sativa $v$. crispa), cebolinha verde ( $A$. fistulosum), coentro (C. sativum), e pimenta de cheiro (C. chinense). Apesar de serem 
plantadas em uma mesma área, desenvolveram, já que o local onde foram plantadas houve a reposição de adubo (excremento de gado).

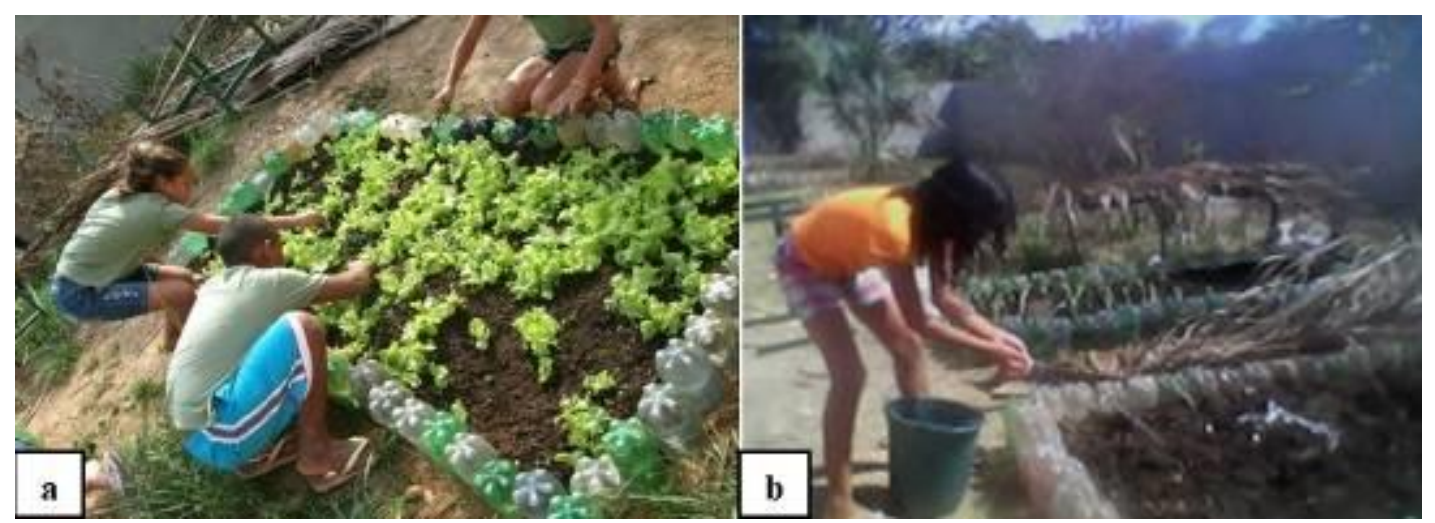

Figura 7: a) Educandos no monitoramento quanto ao surgimento de ervas daninhas na horta escolar; b) Educanda no processo de irrigação da horta escolar. E. M. E. F. Santo Antônio do Praialta - Nova Ipixuna - PA. Fonte: autores (2017).

Na pesquisa realizada no Paraná, pelo Governo do Estado (2012), indicou que a turma de uma Escola ficou responsável em fazer o controle de ervas daninhas e insetos, enfatizando a importância da presença de pássaros no controle dos insetos, uma vez que para ter uma horta orgânica não se pode utilizar de defensivos e fertilizantes químicos para que não haja contaminação do solo. Em Santo Antonio do Praialta, durante os dias em que realizavam a manutenção da horta escolar, os mesmos não tiveram preocupações em exercer o controle sobre os insetos, já que os pássaros presentes no pátio da escola (escola nicho ecológico) fazem o controle dos insetos no âmbito escolar, o que difere do constatado no Paraná.

\section{Desenvolver hábitos alimentares saudáveis a partir da vivência na horta de forma didática para o estudo de ciências naturais}

Quanto ao desenvolvimento dos hábitos alimentares saudáveis, a análise dos dados obtidos, indicou que as olerícolas coletadas em setembro e outubro de 2015 (Figuras 8a e 8b), pela comunidade escolar, foram ofertadas aos educandos (Fundamental I e II) associadas a merenda escolar. Foi notório a satisfação pessoal dos educandos quando receberam a cota da merenda escolar complementada com as hortaliças produzidas pelos educandos na horta escolar (Figuras 8c e 8d).

Todavia, os dados obtidos indicaram também que educandos do ensino fundamental I, composto por setenta e nove educandos, cinquenta $(63,2 \%)$, jogaram os vegetais no lixo. Em relação ao fundamental II, composto por noventa e dois educandos, percebeu-se que trinta e cinco (38\%), jogaram no lixo os vegetais contidos no prato. 


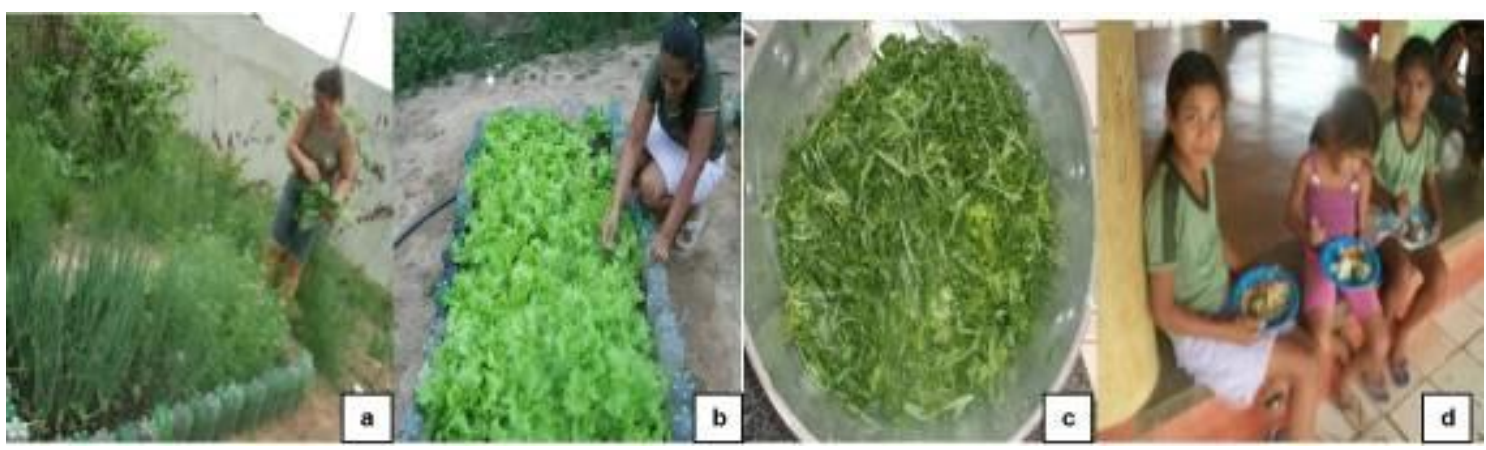

Figura 8: a) Participação da auxiliar de serviços gerais na colheita das hortaliças; b) Diretora da Escola participando da colheita das hortaliças; c) oleícola coletada e pronta para acréscimo na merenda escolar; d) merenda escolar servida. E. M. E. F. Santo Antônio do Praialta. Nova Ipixuna - PA. Fonte: autores (2017).

Em estudo efetuado em Florianópolis - SC, por Cunha, Sousa e Machado (2010), os autores concluíram que há necessidade em incentivar os educandos no consumo de saladas, já que a maioria não gosta. E quando professores explicam a importância da ingestão frutas e verduras aos educandos, com frequência, perguntam se o professor faz dieta, pois, a ingestão verduras, para eles, tem essa concepção. Nesse sentido, entende-se o comportamento dos educandos da E. M. E. F. Santo Antônio do Praialta, em descartar na lixeira, as saladas de hortaliças, já que esse hábito alimentar não faz parte da realidade deles, mas, deve ser trabalhado tanto na escola quanto nas residências.

\section{Quanto a interdisciplinaridade (ciência, matemática e português) ocorrida na visita técnica a horta escolar}

A análise dos dados obtidos para a interdisciplinaridade mostrou que a inserção de outras atividades pedagógicas (pesquisa de campo; elaboração de relatórios; discussões acerca da horta escolar; visitas técnicas a horta escolar) desenvolvidas nos meses de setembro a novembro de 2015, com os educandos do sexto e sétimo ano, o incremento de assimilação dos mesmos, relacionados à Botânica, especialmente quanto à identificação e classificação dos vegetais presentes na horta.

No estudo efetuado em Ouro Preto - MG, por Tavares et al. (2014). Os autores concluíram que a horta escolar trabalhada de formar interdisciplinar, estimulou interesse dos educandos quanto a botânica (ápice caulinar, estrutura foliar - limbo, bainha, pedúnculo). Esse mesmo resultado foi obtido no presente estudo porque também proporcionou o estimulo dos educandos quanto 0 estudo da Botânica.

A análise dos dados para a visita técnica indicou que houve interesse dos educandos da turma do sexto e sétimo ano em sair do espaço formal (sala de aula), para o espaço não formal (visita a horta). Os dados indicaram também que houve maior interesse na forma de monitoramento por escrito, maior receptividade as explicações e a proposta da pesquisadora (Figura 9a), 
quanto a produção das anotações em forma de questionários (Figura 9b) e discutir observações acerca dos cultivos em crescimento na horta e a inserção de insetos (Figura 9c). Pelo desempenho que demonstraram, conclui-se que houve maior interesse pela disciplina ciências com a Língua Portuguesa.

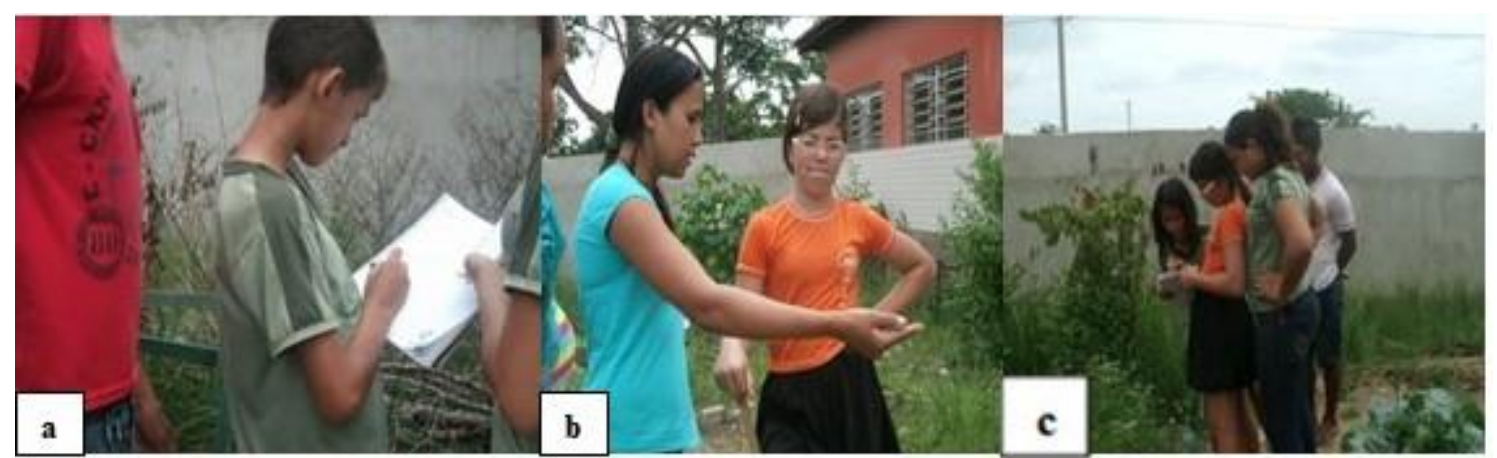

Figura 9: a) Educandos na horta fazendo observação e anotações; b) Interferência da responsável pela pesquisa; c) Educandos em atividades na horta escolar - E. M. E. F. Santo Antônio do Praialta. Nova Ipixuna - PA. Fonte: autores (2017).

Após as observações e anotações solicitadas na visita técnica, houve o retorno para o espaço educacional formal, pois, todos já haviam descritos as observações necessárias:

- Por que não tem lagartas nas plantas?

- Por que não foram encontrados vestígios ou mesmo minhocas no solo?

- Por que algumas plantas desenvolveram mais que as outras, mesmo plantadas em um mesmo período?

- Por que plantas plantadas no mesmo tempo e mesmo ambiente, algumas plantas morrem mesmo estando em um ambiente propício para o seu desenvolvimento?

Os dados analisados quanto a esse debate, indicaram que houve maior participação dos educandos (100\%) envolvidos nessa pesquisa, além da inserção de temas como: cadeia alimentar, desenvolvimento das plantas, os nutrientes presentes no solo, disputa de espaço e fotossíntese.

A pesquisa realizada em Goiânia - GO, por Batista et al. (2013), indicou que na aplicação da disciplina ciência, com ênfase na botânica, deve-se discutir: tipo de cultura, desenvolvimento das plantas (tempo e espaço), fotossíntese, tipos de animais na horta como minhocas (Haplotaxida), formigas (Formicidae), sapos (Bufonidae), lagartas (Brassicaceae), pulgões (Aphididae) (todos esses encontrados na Horta) conhecimento de produtos químicos e orgânicos Com isso comprovou-se que a horta escolar pode ser utilizada como material pedagógico para o ensino de ciências.

A análise dos dados obtidos para o estudo da Taxonomia, indicou que houve desempenho satisfatório porque os educandos foram capazes de elaboram placas com revestimento plástico (Figura 11a e 11b), com os nomes 
populares e científicos de cada olerícolas semeada na horta (Figura 11c), após a proposição e explicação sobre o tema pela educadora.

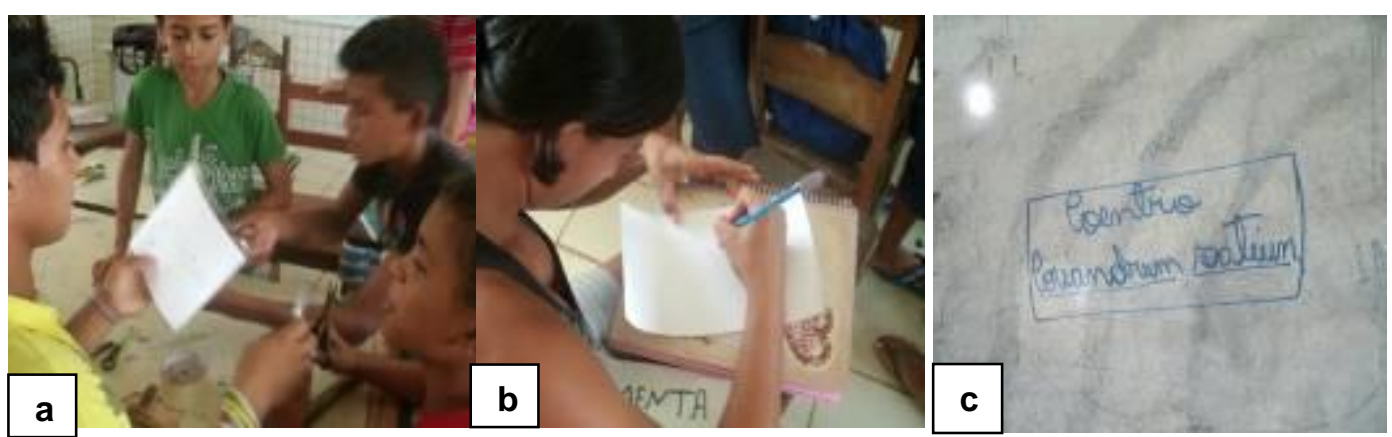

Figura 11: a, b) Educandos elaborando placas de identificação popular e científica; c) Exemplo no quadro magnético de como elaborar as placas - E. M. E. F. Santo Antônio do Praialta Nova Ipixuna -PA. Fonte: autores (2017).

Estudo efetuado em Campinas - SP, por Borges, Cavalli e Proença (2010), sobre o uso da Taxonomia, concluiu que a classificação de vegetais a partir da horta escolar, comprovou que as hortaliças contribuem para o estudo de Botânica. Mediante as atividades didáticas desenvolvidas na horta escolar como, por exemplo: observações e anotações, elaboração de placas com o nome popular e científico, verificação do desenvolvimento dos vegetais, Observação e anotações de componentes vegetais (raiz, caule, folha, flor, fruto). Portanto, os resultados obtidos em Nova Ipixuna corroboram com aqueles obtidos em Campinas.

Quanto a disciplina matemática, a análise dos dados obtidos indicou que os educandos observaram muito bem as diferenças, quanto ao comprimento, largura, espessura, fração decimal e potenciação, entre as folhas de vegetais presentes no âmbito escolar e as olerícolas (Figura 12), e isso melhorou a assimilação quanto aos processos matemáticos analisados.

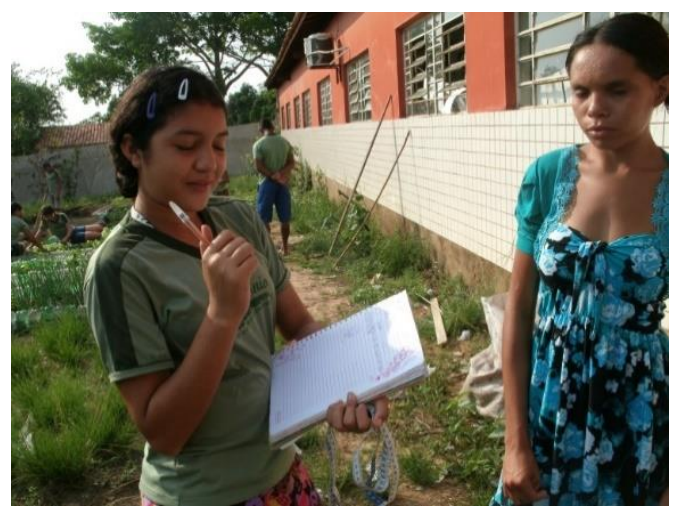

Figura 12: Atividade voltada para o ensino interdisciplinar (ciências e matemática). Observa-se o educando com o diastímetro para mensuração dos canteiros da horta escolar. Fonte: autores (2017) 
$\mathrm{Na}$ pesquisa realizada no município de Francisco Beltrão - PR, na comunidade Rio Tuna, por Trentin e Pereira (2014), os dados obtidos indicaram que, tanto os alunos do 6을 ano do Ensino Fundamental II e a educadora de Matemática, realizaram a medição dos canteiros, com a finalidade de obter medidas necessárias para o cálculo de área. $O$ cálculo de área é necessário para estipular as quantidades de nutrientes necessários na correção do solo. Os materiais utilizados nesta fase foram: tesoura, barbante e fita métrica. Os educandos de Santo Antonio do PraiAlta, realizaram tais mensurações e obtiveram a área total bem como as proporções de nutrientes necessárias à semeadura das olerícolas, com isso, houve melhor assimilação desse tema na matemática, e melhorou a compreensão sobre o mesmo pelos educandos, o que corrobora com os dados obtidos em Francisco Beltrão.

\section{Conclusões}

O uso da horta escolar como ferramenta pedagógica na relação ensinoaprendizado é eficaz tanto para a apreensão do conteúdo ministrado em ciências, matemática e português, bem como para a socialização entre os educandos envolvidos. As ações praticadas para construção e monitoramento da horta escolar, permitem incrementar a relação entre a conservação do solo, produção de alimentos, Educação Ambiental, qualidade do solo (nutrientes, umidade, ausência de predadores naturais, etc.), o que os torna mais responsáveis pela conservação ambiental, além de melhorar a sensibilidade ambiental desses agentes multiplicadores dessa conservação

As disciplinas puderam ser aplicadas extraclasses com mais efetividade e assimilação por parte dos educandos, o que tornou as aulas com maior rendimento e assimilação, melhorou a interpretação do conteúdo por parte dos mesmos, e proporcionou um grau de responsabilidade quanto ao meio ambiente, que poderá gerar, no futuro, agentes multiplicadores da qualidade ambiental, bem como manter o solo produtivo, com a implementação de técnicas agrícolas ambientalmente corretas.

\section{Referências}

AGUIAR, P.C.B. et al. Da Teoria À Prática Em Educação Ambiental. Revista Gestão \& Sustentabilidade Ambiental. v. 6, n. 3, 2017.

ANVISA. Agência Nacional de Vigilância Sanitária. Gerencia Geral de Alimentos. Resolução - CNNPA N. 12 DE 1978. Disponível em: http://www.anvisa.gov.br/anvisalegis/resol/12 78.pdf. Acesso em 09 abril.2018.

BATISTA, I.M. et al. Horta escolar: alimentação como fonte de prazer e sustentação. Universidade Estadual de Goiás. Goiás, s/n, p. 209 -218, 2013.

BORGES, L.C.: CAVALLI, S.B.; PROENÇA, R.P.C. Proposta de classificação de vegetais considerando características nutricionais, sensoriais e de técnicas de preparação. Campinas (SP). Revista Nutrição, Campinas, v. 23, n.4, p. 645 - 654, jul./ago. 2010. 
BRASIL. Lei №. 9795, de 27 de abril de 1999. Disponível em: < http://www.planalto.gov.br/ccivil 03/decreto/1980-1989/D97955.htm>. Acesso em 04 out.2017

BRAZ, B.C. et al. Modelagem matemática na construção de uma horta. Encontro Paranaense em Modelagem em Educação Matemática. 3. 2009. Anais...Campo Mourão: UNICENTRO, p.291-300.

COIMBRA, A.S. Interdisciplinaridade e Educação Ambiental: Integrando Seus Princípios Necessários. Programa de Pós-Graduação em Educação Ambiental. Universidade Federal de Juiz de Fora - UFJF. 2010. Disponível em: http://www.ufff.br/virtu/files/2010/03/artigo-1a2.pdf. Acesso em 09 abr.2018.

CONRADO, L.M.N.; SILVA, V.U. Educação Ambiental e interdisciplinaridade: um diálogo conceitual. Revista Gestão \& Sustentabilidade Ambiental, v. 6, n. 3, 2017.

CORBARI, F. et al. Educação Ambiental Agroecológica para Público Estudantil no Oeste do Paraná - Universidade e Escolas Juntos pela Sustentabilidade. Paraná (PR): I Congresso Paranaense de Agroecologia, v. 9, n. 1, 2014.

CRIBB, S.L.S.P. Contribuições da Educação Ambiental e Horta Escolar na Promoção de Melhorias ao Ensino, à Saúde e ao Ambiente. Rev. Eletr. do Mestr. Profis. em Ensino, Saúde e Ambiente, Rio Grande do Sul, v. 3, n. 1, p. 42-60, jan/abr. 2010.

CUNHA, E.; SOUSA, A.A.: MACHADO, N.M.V. Alimentação orgânica e as ações educativas na escola: diagnóstico para educação em saúde e nutrição. Florianópolis (SC): Ciências \& Saúde Coletiva, v. 15, n.1, 2010.

FERREIRA, V.G.M. et al. Educação Ambiental e o Ensino de Ciências: a horta escolar como instrumento facilitador no processo de ecoalfabetização. Congresso Latino-americano de Botânica. Congresso Nacional de Botânica. 54

. Anais eletrônicos...Salvador - BA. 2014. Disponível em: $<$ http://www.botanica.org.br/trabalhos-cientificos/65CNBot/5083-ENB.pdf> Acesso em:10 nov. 2017

FROES, E, K. et al. Hortas Escolares: Uma Proposta De Integração Da Horta Às Disciplinas Do Ensino Fundamental Nas Escolas Do Alto Vale Do Itajaí. In: MOSTRA NACIONAL DE INICIAÇÃO CIENTÍFICA E TECNOLOGIA INTERDISCIPLINAR. 8. Santa Rosa. Anais eletrônicos...Santa Rosa do Sul: Campus IFC.2015 Disponível em: http://eventos.ifc.edu.br/wpcontent/uploads/sites/5/2015/10/HORTAS-ESCOLARES-UMA-PROPOSTA-

DE-INTEGRA\%C3\%87\%C3\%83O-DA-HORTA-\%C3\%80S-DISCIPLINAS-DO-

ENSINO-FUNDAMENTAL-NAS-ESCOLAS-DO-ALTO-VALE-DO-

ITAJA\%C3\%8D.pdf. Acesso em: 04 out.2017.

GALVÃO, S.R.S.: SALCEDO, I.H.; OLIVEIRA, F.F. Acumulação de nutrientes em solos arenosos adubados com esterco bovino. Brasília (DF): Pesquisa Agropecuária, v.43, n.1, 2008.

revista brasileira educação ambiental 
GOVERNO DO ESTADO DO PARANÁ. O professor PDE e os desafios da Escola Pública Paranaense: produção didático-pedagógicas. Secretária de Educação. Paraná, v. 2, p. 1- 44, 2012.

GIL, A.C. Métodos e técnicas da pesquisa social. 6 ed. São Paulo: Atlas, 2008, $197 \mathrm{p}$.

IBGE. INSTITUTO BRASILEIRO DE GEOGRAFIA E ESTATÍSTICA, 2014. Disponível: <http://cidades.ibge.gov.br/xtras/home.php?lang=>. Acesso em: 18 mai. 2017.

MALACARNE, W.; ENISWELER, K.C. Formação do pedagogo e ensino de ciências: a horta escolar como espaço para diálogos sobre educação ambiental. Educere et Educare, v. 9, n. 17, 2014

PEREIRA, B. F. P.; PEREIRA, M. B. P.; PEREIRA, F. A. A. Horta escolar: enriquecendo 0 ambiente estudantil. Revista Brasileira de Educação Ambiental, v. 7, n. 1, 2012.

PMNI. REFEITURA MUNICIPAL DE NOVA IPIXUNA. Plano Diretor do Município de Nova Ipixuna. Nova Ipixuna - Pará, s/n, p. 1 - 202, 2006. Disponível em: <http://www.seidurb.pa.gov.br/pdm/nova ipixuna/PDM.pdf> Acesso em: 24 abr. 2017.

RODRIGUES, I. O. F.; FREIXO, A. A. Representações e Práticas de Educação Ambiental em Uma Escola Pública do Município de Feira de Santana (BA): subsídios para a ambientalização do currículo escolar. Rev. Bras. de Ed. Ambiental, v. 4, 2009.

SANTANA, L.M.S. et al. Horta Escolar como Recurso no Ensino de Ciências na Perspectiva da Aprendizagem Significativa. Rev. Cienc. Exatas e Tecnol., v.9, n. 9, 2014.

SBAZÓ JÚNIOR, A M. Educação Ambiental e gestão de resíduos sólidos. 3 ed. São Paulo: Ridel, 2010.

SILVA, E.C.R.; FONSECA, A.B. Hortas em escolas urbanas, Complexidade e transdisciplinaridade: Contribuições para a Educação Ambiental e para a Educação em Saúde. Revista Brasileira de Pesquisa em Educação em Ciências, v. 11, n. 13, 2011.

SILVA, D.C.F. et al. Horta escolar: interdisciplinaridade, reflexão ambiental e mudanças de hábitos alimentares. Revista de Ciências Exatas e Tecnologia, v. 9, n.9, 2014.

SILVEIRA, D.T.; CÓRDOVA, F.P. A pesquisa científica. In: GERHARDT, T.E.; SILVEIRA, D.T. Métodos de Pesquisa. Porto Alegre: UFRGS, 2009, p. 31 41.

SIQUEIRA, F.M.B. et al. Horta Escolar como ferramenta de Educação Ambiental em uma Escola Estadual no município de Várzea Grande - MT. In: CONGRESSO BRASILEIRO DE GESTÃO AMBIENTAL. 8. 2016. Anais... Campina Grande: ... v. II, n. 062, [s/n]. 
TAVARES, B.V. et al. Os desafios na implantação de um projeto de horta escolar. Ouro Preto (MG): XXI Seminário de Iniciação Científica da UFOP, $\mathrm{s} / \mathrm{n}, \mathrm{p} .1-9,2014$.

TAVARES, L.H.W.; ROGADO, J. Múltiplas possibilidades de trabalho nas aulas de Ciências por meio da horta escolar. Ensino, Saúde e Ambiente, v.1, n. 2, 2008.

TRENTIN, E.S.: PEREIRA, L.B.C. Escola do Campo: Ensinando e Aprendendo no Contexto da Horta Métrica. In: Anais do Encontro Paranaense de Educação Matemática. 12. Paraná (PR): Universidade Tecnológica Federal do Paraná, p. $1-13$, 2014.

Disponível em:

http://sbemparana.com.br/arquivos/anais/epremxii/ARQUIVOS/COMUNICACO ES/CCAutor/CCA026.PDF.. Acesso em: 10 dez. 2017.

Link acessado: http://www.mma.gov.br/informma/item/9410-apol\%C3\%ADtica-dos-5-r-s.. $\quad$ Acesso em: 09 abr. 2018. 